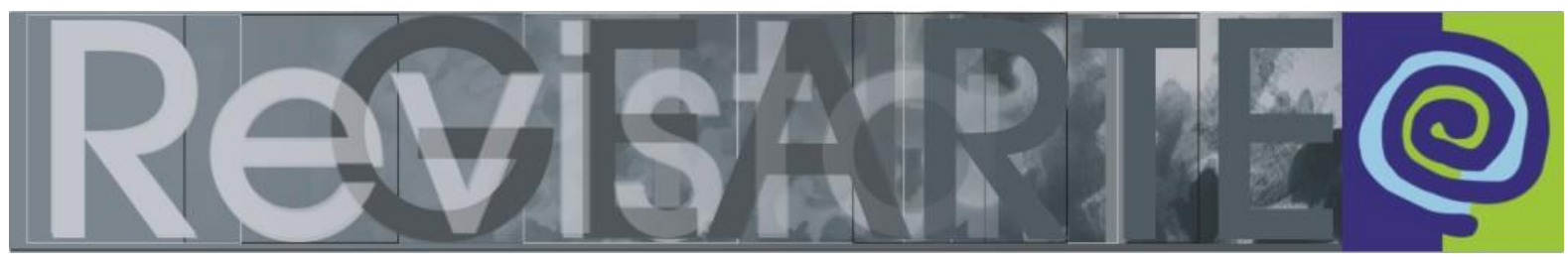

ISSN 2357-9854

\title{
Docência superior mediada pela imagem veiculada pelas tecnologias digitais - dicotomia entre a dimensão instrumental e o discurso das visualidades
}

\author{
Rosilei Mielke (Universidade Católica Dom Bosco - UCDB, Campo Grande/MS, \\ Brasil; Universidade Federal da Paraíba — UFPB, João Pessoa/ PB, Brasil) \\ Blanca Martín Salvago (Universidade Católica Dom Bosco — UCDB, Campo \\ Grande/MS, Brasil)
}

\begin{abstract}
RESUMO - Docência superior mediada pela imagem veiculada pelas tecnologias digitais dicotomia entre a dimensão instrumental e o discurso das visualidades - Este artigo discute a utilização da imagem veiculada pelas tecnologias digitais no processo de mediação na docência do ensino superior, a dicotomia entre a sua dimensão instrumental e o discurso das visualidades, com uma abordagem sobre a cultura visual e a educação contemporânea. Analisa-se as demandas dos estudantes em relação à imagem e às tecnologias digitais, as posturas apresentadas pelos docentes $\mathrm{e}$ algumas posturas que a realidade exige para o desenvolvimento de uma perspectiva pedagógica interativa, potencializadora, emancipadora e participativa. As investigações, que neste primeiro momento contemplam a pesquisa bibliográfica, apontam para um entendimento da inserção das imagens veiculadas pelas tecnologias digitais como fundamento, como conteúdo e como construtora de conhecimento, pode ser um caminho para transformações significativas no processo de ensinoaprendizagem na formação de novos docentes.
\end{abstract}

PALAVRAS-CHAVE

Imagem. Tecnologias digitais. Docência no ensino superior.

RESUMEN - Enseñanza superior mediada por la imagen presentada por las tecnologías digitales - dicotomía entre dimensión instrumental y discurso de visualidades - El artículo discute la utilización de la imagen presentada por las tecnologías digitales en el proceso de mediación en la docencia de la educación superior, el contraste entre su dimensión instrumental y el discurso de las visualidades, desde un enfoque sobre la cultura visual y la educación contemporánea. Se analiza el que requiere los estudiantes en relación a la imagen y las tecnologías digitales, las posturas presentadas por los profesores y algunas posturas que la realidad exige para el desarrollo de una perspectiva pedagógica interactiva, potenciadora, emancipadora y participativa. Las investigaciones, que en este primero momento contemplan la pesquisa bibliográfica, apuntan para una compreensión de la inserción de las imágenes presentadas por las tecnologías digitales como fundamento, contenido y constructora de conocimiento, puede ser uno camino para las transformaciones significativas en el proceso de enseñanza-aprendizaje en la formación de los profesores.

PALABRAS CLAVE

Imagen. Tecnologías digitales. Docencia de la educación superior. 


\section{Introdução}

A sociedade contemporânea preconiza as visualidades que destacam a imagem $^{1}$, as tecnologias digitais ${ }^{2}$ e a cultura visual ${ }^{3}$. As tecnologias digitais aliadas ao uso da imagem ocupam também o cenário do ensino superior, se configurando, uma realidade necessária e inevitável. Investiga-se a dicotomia entre a dimensão instrumental e o discurso das visualidades na utilização da imagem, veiculada pelas tecnologias digitais, nas práticas docentes no ensino superior; uma análise de como os docentes relacionam as dimensões pedagógica e tecnológica no uso das imagens.

A questão em voga é se o uso da imagem veiculada pelas tecnologias digitais revela a tônica da docência no ensino superior, provocando outra postura dos docentes, ou se existe uma perspectiva apenas instrumental nas suas práticas pedagógicas.

O interesse pela pesquisa está ligado à compreensão de que se vive um período de mudanças no campo da educação contemporânea, no qual a visualidade, inevitavelmente, possui presença e influência no cotidiano das pessoas. A relevância está na busca por identificar, diagnosticar e analisar a prática docente em relação ao objetivo e compreensão pedagógica acerca do uso da imagem digital e a relação entre processos de conhecimento, a tecnologia. Relaciona-se de forma intrínseca com a área de conhecimento e ensino de artes visuais, na qual a autora se insere como educadora.

1 "Além da beleza estética, uma imagem personifica um significado que é, ao mesmo tempo, transitório e intimamente ligado a qualquer pintura, propaganda de roupas, sequência de computação gráfica ou filme pós-moderno. Essa objetivação do significado emerge por meio de interpretações da relação entre o que é representado e sua representação; entre o significante, 0 significado e o signo." (BARBOSA, 2010, p. 126).

2 Entende-se como tecnologias digitais os equipamentos desenvolvidos a partir dos anos 1990, que compõem a área da informática, além de outros recursos e linguagens digitais de que atualmente dispõe-se e que podem contribuir para o processo educativo interativo.

3 A cultura visual é um campo de estudos recente. Enquanto área, a cultura visual difere das anteriores por tratar das questões de visualidade relativas a imagens e objetos artísticos e nãoartísticos, artefatos, tecnologias e instituições da representação visual (DIAS, 2012, p. 169). O uso do termo "cultura visual" reflete as influências, proliferação, proficiência e poder da visualidade na construção do conhecimento acadêmico e formação do senso crítico frente à realidade, as TICs e às próprias imagens. 
Com esses pressupostos, se realizou uma pesquisa bibliográfica em que os autores como: Hernández (2000; 2005; 2013), Victorio Filho; Correia (2013), Almeida (2014), Campos (2013), Dias (2012), Barbosa (2010), Domingues (2014), Miranda (2013), entre outros, possibilitaram estabelecer diálogo entre pesquisas e teorias, gerando novos questionamentos.

Apresenta-se a análise em três seções. A primeira apresenta uma abordagem geral acerca da educação e o imbricamento da imagem e das tecnologias digitais. A segunda seção reflete criticamente sobre a realidade da mediação da imagem digital enquanto instrumentalidade e/ou fundamento na docência universitária. A terceira seção trata das considerações finais em formato de possibilidades para continuidade e novas pesquisas.

\section{A educação e o imbricamento da imagem e das tecnologias digitais}

A educação contemporânea supõe o aprendizado a partir da apreensão da realidade e do contexto, das tecnologias da informação e comunicação - TICs, da interatividade e de outras perspectivas relativas à visualidade. É possível tratar a imagem como conteúdo em si mesma no universo acadêmico. A imagem, a partir dos princípios da cultura visual, infere uma complexa relação com o universo acadêmico de descobertas e resistências, como um elemento potencializador da construção e comunicação do conhecimento.

Para Oliveira (2001, p. 6), "uma imagem é definida como um texto, o que implica que toda imagem é um tecido de significação tramado coesamente". Os códigos verbais necessitam de uma imagem mental como referência para produzir sentido; são igualmente, códigos verbais e não verbais, convencionados pela sociedade, dependendo da subjetivação do sujeito para sua interpretação.

Em um passado recente, a imagem era para ser contemplada. No momento presente está para ser captada e participada. Hernández (2013) sustenta que o relevante não são as imagens que chegam ao aluno pelas diversas mídias e tecnologias, mas as relações que mantém com elas ao interagir. 
A imagem é uma construção social que reflete nas instituições, nos meios de comunicação, nas artes e nos diferentes tipos de sujeitos. Portanto, o educador contemporâneo opera com elementos da gramática da imagem quase que todo o tempo. Nesse sentido, o olhar crítico para a imagem "é um olhar na vida da sociedade, e, na vida da sociedade, representada nesses objetos." (HERNÁNDEZ, 2000, p. 53). A importância das imagens nos processos da construção da cultura, bem como na formação do sujeito que a produz, deve ser considerada.

Assim sendo, as imagens são apropriadas por sujeitos que as (re)significam segundo suas construções/concepções de vida. Elas ocupam o cotidiano do mundo cada vez mais permeado pelas TICs e pelas práticas visuais, (des)construindo identidades e, portanto, (re)formando indivíduos. (DIAS et al., 2012, p. 169).

A educação, a imagem $e$ as tecnologias digitais estão entrelaçadas e imbricadas. A cultura contemporânea propiciou um ambiente para a integração da tecnologia, da inteligência e da emoção. Conforme Barbosa (2010, p. 111), "a tecnologia não apenas transformou as práticas cotidianas, mas também os modos de produção intelectual." Como as visualidades, as tecnologias digitais passaram a influenciar o cotidiano das pessoas. Julga-se importante o domínio dessas ferramentas mediadoras e, principalmente do desenvolvimento de uma análise estético/crítica dessas imagens e, por conseguinte, da própria sociedade e indivíduo "midiatizado".

\begin{abstract}
As tecnologias se tornam instrumentos sensíveis que oferecem a nossa imaginação realidades vividas num mundo real. O que interessa não é o poder do computador, mas novas chaves para a imaginação das pessoas que podem interagir com as imagens propostas. [...] A interatividade se oferece em trocas de informações imediatas, modificando as instâncias de produção e recepção em escalas planetárias. (DOMINGUES, 2014, p. 54).
\end{abstract}

Essa perspectiva educativa poderia gerar transformação se democratizada. Campos (2013, p. 28) salienta que a imagem é admitida como um espaço de consolidação do discurso científico e na edificação de determinadas disciplinas, possuindo a capacidade de "atormentar imaginações e desejos", causar "violentas reações de contestação". Por isso, gera receios e tentativas de afastamento da sala de aula. O uso da imagem no universo acadêmico encontra relutância e obstáculos à sua plena inclusão devido ao "argumento da polissemia das imagens", sua 
especificidade latente. Dessa forma, a imagem como veículo, produção e conhecimento, é colocada em "posição periférica" no universo científico acadêmico.

O que se constitui para o campo das artes visuais como um valor, pode não ser para as "verdades" dos cânones sacralizados da Academia, herança do rigor positivista e da psicologia behaviorista de filósofos como John Locke. Este manifestou sua cautela quanto ao discurso figurativo como artifício que "não serve para nada mais do que insinuar ideias erradas, mover paixões e, portanto, confundir o julgamento." (LAKOFF; JOHNSON, 1980, p. 191).

No entanto, essa realidade começa a mudar para atender às demandas apresentadas pelas novas gerações, fixadas nas TICs e na imagem digital. A sociedade em geral, mas, principalmente as gerações nascidas a partir dos anos noventa, consomem cotidianamente imagens digitais popularizadas através das TICs. Em muitos casos sem uma postura crítica de leitura e diálogo com a imagem, sendo afetados e reproduzindo os modelos culturais em que estão imersos.

A imagem digital, em uma perspectiva da cultura visual, "situa questões, institui problemas e aponta possibilidades para a educação em geral." (DIAS et al., 2012, p. 151). Pode auxiliar em práticas pedagógicas que contemplem a complexidade da cultura contemporânea, a coletividade na construção do conhecimento.

Domingues (2014, p. 58) menciona a exploração do computador e dos espaços da cibercultura como campo de múltiplas possibilidades que vão além da condição de ferramenta. Compreende a mediação das tecnologias e imagens digitais na vida do indivíduo contemporâneo como vivência positiva de simbiose do sujeito com a máquina por "relações corpo/máquina". Mas, em contraponto, há teorias que lançam um "olhar apocalíptico" sobre esta realidade, comparando a imagem eletrônica (digital) ao "caráter alucinatório e alucinógeno", similar às drogas.

\section{Imagem digital e docência universitária: entre a instrumentalidade e o fundamento}

$\mathrm{Na}$ visão de alguns autores pesquisados, o uso da imagem veiculada pelas tecnologias digitais, em sala de aula, incentiva a postura crítica também em relação 
aos "sistemas culturais". Segundo Campos (2013, p. 33), o analfabetismo visual acadêmico é "paulatinamente ultrapassado por uma nova voga de investigadores com ampla capacidade de diálogo com as tecnologias, designadamente digitais, e com elevado domínio dos códigos de comunicação visuais." Pode-se dizer que a imagem concilia as funções estética e epistêmica, não se justificando a sua utilização apenas como instrumento ou recurso de explanação de conteúdo na prática docente no ensino superior. Para Charréu (2012) e autores como Pretto (1996), Pimentel (2002) e Miranda (2013) ainda falta a utilização efetiva das imagens nessa perspectiva, na prática cotidiana dos docentes.

A imagem digital tem a característica de nos conectar com o mundo. Cao (2010, p. 188) afirma que, nessa perspectiva, "o esquema educativo aluna/o-conteúdosociedade pode se articular a partir da imagem ao se trabalhar com a nossa própria imagem, a imagem do mundo que percebemos, e isso permite a articulação de conteúdos humanos, artísticos e técnicos".

É evidente o desfio de se utilizar a visualidade do cotidiano do aluno na pesquisa. Exige a criação de novas possibilidades metodológicas, uma vez que as imagens "não seriam a superfície dos contextos dos quais emergem", mas seriam "o corpo do acontecimento" (VICTORIO FILHO; CORREIA, 2013, p. 51).

Em se tratando de busca por novas possibilidades, alguns docentes, especialmente os ligados à área de ensino de arte, pautam suas pesquisas em práticas pedagógicas recentes a partir da cultura visual. Para ampliar o uso da tecnologia, sobretudo na educação, é preciso pensar as relações entre tecnologia, imagem e processo de conhecimento; o que denota uma preocupação sólida e crescente com o tema.

Algumas experiências são desenvolvidas, atualmente no Brasil, no âmbito acadêmico em universidades, tendo como foco práticas pedagógicas com postura e abordagem transdisciplinar, envolvendo a imagem e as TICs, permeados pela ideia de aproximação dos conteúdos com o cotidiano. Uma dessas experiências 
apresentadas por Dias e outros autores (2012) que pode ilustrar esta constatação, é a do projeto Arte/Fatos ${ }^{4}$.

Pimentel (2002, p. 117), no início dos anos dois mil, chamava a atenção para a imprescindível "preparação adequada dos professores" para saberem utilizar e explorar as tecnologias colocadas à disposição dos estudantes, a fim de "realmente propiciar o aprendizado".

Caberia ao professor "a tarefa de estar sempre em contato com a produção de imagens do seu tempo e atento às imagens consumidas por seus alunos, resgatando na cultura da imagem o que é relevante para a formação do indivíduo" (ALMEIDA, 2014, p. 62), uma vez que, no contexto cultural contemporâneo, a experiência cotidiana dos alunos universitários é percorrida por uma espiral de imagens digitais que se movimentam através de múltiplas situações, contextos e meios.

Os alunos sentem-se mais atraídos a modos de produção, circulação e legitimação de saberes que envolvam os ambientes digitais, "talvez, o local em que esses deslocamentos se produzem com maior celeridade" (PLA, 2013, p. 173). A velocidade dá a tônica às comunicações e troca de informação. Assim, não é ousadia concluir que as aulas expositivas tradicionais não contemplam seus anseios. As recentes tecnologias podem oferecer a educação a distância, como chats, grupos ou listas de discussão, correio eletrônico, ambientes virtuais, entre outros recursos digitais que podem colaborar significativamente para tornar o processo educativo mais atraente.

O uso da imagem digital como instrumentalidade "esvazia esses recursos de suas características fundamentais, transformando-os apenas num animador da velha educação, que se desfaz velozmente, uma vez que o encanto da novidade também deixa de existir" (PRETTO, 1996, p. 114). Essa questão necessita ser pensada nas práticas docentes com empenho e seriedade, para se desenvolver novas experiências

4 Projeto vinculado ao Laboratório de Visualidades e Educação, sediado no Departamento de Artes Visuais do Instituto de Artes da Universidade de Brasília - UNB, que contou com recursos do Programa de Consolidação das Licenciaturas - Prodocência. 
pedagógicas que provoquem confrontos de discursos e fomentem a participação dos alunos na sua construção.

$\mathrm{Na}$ atual reflexão é pertinente o pensamento de Freire (1995, p. 60) de que é necessário "aprender a re-ler nossa realidade. A aprendizagem da re-leitura implica (...) o aprendizado de nova linguagem. Não posso re-ler (...) se não melhoro os velhos instrumentos de análise, se não invento novos instrumentos." Para tanto, é urgente qualificar o ensino superior, nos cursos de licenciatura, por seu caráter de primeiro multiplicador da construção do conhecimento, partindo das realidades que envolvem os alunos e docentes, a cultura e as visualidades. "As tecnologias da informática, sendo usadas como quadro e giz, serão só mais um recurso." (CAMPOS, 2002, p. 6364).

O autor segue defendendo que oferecer uma formação inicial ao docente, com as novas tecnologias, é dar "ferramentas" para torná-lo capaz de saber aprender, de compreender e se dispor a mudanças, prazerosamente. Ter consciência dessa realidade pode também despertar a necessidade de formação contínua e significativa para suprir as exigências educacionais, para tentar superar o papel tradicional dos docentes. O papel do docente pode assumir uma dimensão essencialmente crítica, deixando de ser um consumidor passivo dessas tecnologias, para se tornar um pesquisador e um produtor ativo de cultura, a partir da implementação de outras práticas pedagógicas. Não há mais espaço para transmissão de conhecimento, somente.

Miranda (2013, p. 325) reflete em relação à atividade acadêmica nas universidades, mas também em outros âmbitos da vida, igualmente fragmentada, que a potencialidade de transversalidade da imagem pode gerar novas indagações e práticas, contendo possibilidade de uma prática do diálogo e do encontro. Possibilitaria a real descompartimentalização das disciplinas e áreas do conhecimento na Academia, gerando processos de ensino-aprendizagem abertos, contínuos, não lineares e dialógicos. Como completa Moran (2009, p. 18), "o conhecimento não é fragmentado, mas interdependente, interligado, intersensorial". 
Os meios tecnológicos, apresentados por autores pesquisados, como utilizados pelos docentes, são os celulares e aparelhos digitais para construção de imagens e textos, blogs na internet, sites de pesquisa na internet, além de ferramentas, programas e aplicativos de edição, produção e veiculação de textos e imagens estáticas e em movimento, ambientes virtuais. Significa que, em um contexto geral, os meios mais utilizados ainda são de extensão visual digital, sendo o computador e suas versões portáteis, como tablet e ipod, o grande realimentador da visualidade em nossa sociedade imagética. A questão pertinente está no como utilizam as imagens visualizadas e intercambiada por estes meios.

Como afirma Moran,

O cinema, o rádio, a televisão, trouxeram desafios, novos conteúdos,
histórias, linguagens. Esperavam-se muitas mudanças na educação, mas as
mídias sempre foram incorporadas marginalmente. A aula continuou
predominantemente oral e escrita, com pitadas de audiovisual, como
ilustração. Alguns professores utilizavam vídeos, filmes, em geral como
ilustração do conteúdo, como complemento. Eles não modificavam
substancialmente o ensinar e o aprender, davam um verniz de novidade, de
mudança, mas era mais na embalagem. (MORAN, 2009, p. 101).

Essa forma de encarar as tecnologias digitais continua em muitas realidades. Em contraponto a esta prática, Hernández (2005) defende estratégias pedagógicas que possibilitem a reconstrução de conhecimentos por meio da criação de situações de vivências, convivência e colaboração, com total abertura à diversidade que se encontra em todo grupo.

Cabe perguntar se uma formação visual estético-crítica para os docentes poderia gerar mudanças no fazer pedagógico, o que remete à necessidade de atualizar e sincronizar o que e como se ensina e se aprende com base nas demandas atuais, que poderão de fato inserir os alunos como futuros docentes construtores de cultura e saberes. Talvez, por essa razão, a maioria dos autores pesquisados defende o uso das imagens como elemento para ser significado, contextualizado e ter o envolvimento e participação dos alunos em todo o processo de construção do conhecimento. 


\section{Considerações Finais}

A educação acadêmica atual, nos cursos de licenciatura, está em descompasso com a sociedade digital. Os autores reconhecem que as IES conservam certa dificuldade em instrumentalizar os futuros docentes para transporem o papel de espectadores para atores/sujeitos das pedagogias contemporâneas, que incluem o discurso das visualidades e superam a dicotomia em relação ao uso da imagem apenas como instrumento e recurso didático.

Identifica-se que os docentes possuem uma visão reduzida da importância da imagem veiculada pelas tecnologias digitais, devido a uma possível "alfabetização funcional visual". Possuiriam contato frequente com essas imagens, porém com visão transmissiva estudando-a e usando-a como princípio operacional.

Neste contexto, docente e aluno necessitam buscar a construção compartilhada do conhecimento e de saberes. Porém, o atraso tecnológico digital do docente pode tornar-se um risco de exclusão, tanto para ele quanto para alunos e para saberes necessários à instrumentalização crítica.

As imagens da cultura visual e digital podem auxiliar no aprendizado significativo. Faltaria abertura aos docentes para superar medos e resistências em relação à mediação da imagem, das TICs e ao ensino/aprendizagem participativo? Há que se concretizar a ruptura com antigas práticas pedagógicas embasadas em saberes compartimentados. A imagem ainda não deixou a marginalidade para responder e se alinhar às exigências da sociedade.

Entretanto, o aluno aprenderia significativamente, no ensino superior, se fosse instigado a investigar o texto visual como conteúdo, como processo de construção de conhecimento e como expressão de saberes, reorganizando-os como uma "teia", que gera interpretações críticas. Mas constata-se que a pesquisa de docentes e alunos, lentamente e consistentemente, está conseguindo mudar esses processos nas IES.

A partir da pesquisa com autores que discorreram sobre o tema, se considera que há poucas bibliografias. A dificuldade aumenta quando se procura diagnosticar a dicotomia no uso da imagem nas práticas pedagógicas nos cursos de licenciatura. 
Entretanto, se analisa que a pesquisa atingiu parte considerável dos objetivos propostos. Dadas a essas considerações, se percebe que seria necessário, para aprofundar a pesquisa, a realização da pesquisa de campo, que abrangesse diversos cursos de licenciatura e Instituições de Ensino Superior.

\section{Referências}

ALMEIDA, Cláudia Zamboni de. As relações arte/tecnologia no ensino da arte. In. PILLAR, Analice Dutra (Org.). A educação do olhar no ensino das artes. 8. ed. Porto Alegre: Mediação, 2014. p.61-72.

BARBOSA, Ana Mae. Dilemas da Arte/Educação como mediação cultural em namoro com as tecnologias contemporâneas. In:___ (Org.). Arte/educação contemporânea: consonâncias internacionais. 3. ed. São Paulo: Cortez, 2010. p. 98-112.

CAMPOS, Neide Pelaez. A construção do olhar estético-crítico do educador. Florianópolis: Editora da UFSC, 2002.

CAMPOS, Ricardo. Imagem e tecnologias visuais em pesquisa social: tendências e desafios. In: MARTINS, Raimundo; TOURINHO, Irene (Orgs.). Processos e práticas de pesquisa em cultura visual e educação. Santa Maria: Ed. da UFSM, 2013. p. 21-48.

CAO, Marián López F. Lugar do outro na Educação Artística: olhar como eixo articulador da experiência: uma proposta didática. Tradução de Maria Emilia Sardelich. In: BARBOSA, Ana Mae (Org.). Arte/educação contemporânea: consonâncias internacionais. 3. ed. São Paulo: Cortez, 2010. p. 187226.

CHARRÉU, Leonardo. Imagens Globais, Cultura Visual e Educação Artística: impacto, poder e mudança. In: MARTINS, Raimundo; TOURINHO, Irene (Orgs.). Culturas das imagens: desafios para a arte e para a educação. Editora UFSM: Santa Maria, 2012. p. 97-113.

DIAS, Belidson et al. Arte/Fatos: cultura visual e formação de professores. In: FERNANDES, Maria Lídia Bueno (Org.). Trajetórias das licenciaturas da UNB: a experiência do Prodocência em foco. 2.ed. rev. ampl. Brasília: Editora Universidade de Brasília, 2012.

DOMINGUES, Diana. Tecnologias, produção artística e sensibilização dos sentidos. In: PILLAR, Analice Dutra (Org.). A educação do olhar no ensino das artes. 8. ed. Porto Alegre: Mediação, 2014. p. 31-60.

FREIRE, Paulo. À sombra desta mangueira. 2. ed. São Paulo: Olho d'água, 1995.

HERNÁNDEZ, Fernando. Cultura visual: mudança educativa e projeto de trabalho. Tradução de Jussara Haubert Rodrigues. Porto Alegre: Artes Médicas Sul, 2000.

HERNÁNDEZ, Fernando. De qué hablamos cuando hablamos de cultura visual? Educação \& Realidade, Porto Alegre, v. 30, n. 2, p. 9-35, 2005.

HERNÁNDEZ, Fernando. Pesquisar com imagens, pesquisar sobre imagens: revelar aquilo que permanece invisível nas pedagogias da cultura visual. Tradução: Mirela Adriele da Silva Castro. In: MARTINS, Raimundo; TOURINHO, Irene (Orgs.). Processos e práticas de pesquisa em cultura visual e educação. Santa Maria: Ed. da UFSM, 2013. p. 77-95.

LAKOFF, George; JOHNSON, Mark. Metafhors we live by. Chicago: University of Chicago Press, 1980.

MIRANDA, Fernando. Imagens da arte, da ciência e da tecnologia: pesquisar a partir da cultura visual. Tradução: Danilo de Assis Clímaco. In: MARTINS, Raimundo; TOURINHO, Irene (Orgs.). Processos e práticas de pesquisa em cultura visual e educação. Santa Maria: Ed. da UFSM, 2013. p. 321-344.

MORAN, José Manuel. A educação que desejamos: novos desafios e como chegar lá. São Paulo: Papirus, 2009. 
OLIVEIRA, Ana Claudia Mei Alves de. Lisibilidade da imagem. Revista da Fundarte, Montenegro, v. 1, n. 1, p. 4-7, jan./jun. 2001.

PIMENTEL, Lucia Gouvêa. Tecnologias contemporâneas e o ensino da arte. In: BARBOSA, Ana Mae (Org.). Inquietações e mudanças no ensino da arte. São Paulo: Cortez, 2002. p. 113-121.

PLA, Alfred Porres. Conversações na aula de cultura visual. Tradução de Danilo de Assis Clímaco e Inés Olivera Rodriguéz. In: MARTINS, Raimundo; TOURINHO, Irene (Orgs.). Processos e práticas de pesquisa em cultura visual e educação. Santa Maria: Ed. da UFSM, 2013. p. 153-180.

PRETTO, Nelson De Luca. Uma escola sem/com futuro: educação e multimídia. Campinas: Papirus, 1996.

VICTORIO FILHO, Aldo; CORREIA, Marcos Balster Fiore. Ponderações sobre aspectos metodológicos da investigação na cultura visual: seria possível metodologizar o enfrentamento elucidativo das imagens? In: MARTINS, Raimundo; TOURINHO, Irene (Orgs.). Processos e práticas de pesquisa em cultura visual e educação. Santa Maria: Ed. da UFSM, 2013. p. 49-60.

\section{Rosilei Mielke}

Licenciada em Artes Visuais pela Universidade do Contestado - UNC; Pós-graduação Lato Sensu: Especialista em Linguística, Letras e Artes - Área de Concentração em Arte-Educação: Fundamentos e aplicação, pela Universidade do Contestado - UNC. Especialista em Docência no Ensino Superior da Universidade Católica Dom Bosco - UCDB; Mestranda do Programa de Pós-graduação Associado em Artes Visuais - Universidade Federal da Paraíba - UFPB / Universidade Federal de Pernambuco UFPE. Membro do Grupo de Pesquisa em Educação e Artes Visuais - GPEAV.

E-mail: rosimke@yahoo.com.br.

Currículo: http://lattes.cnpq.br/5620239848630718

\section{Blanca Martín Salvago}

Bacharel em Teologia pela Faculdade de Teologia de Granada (Espanha). Licenciada em Letras pela Universidade Católica Dom Bosco (Campo Grande - MS). Mestre em Ciências Bíblicas pelo Pontifício Instituto Bíblico de Roma (Itália). Atualmente é Professora Titular da Universidade Católica Dom Bosco (UCDB - Campo Grande-MS), com o cargo de Coordenadora Pedagógica da UCDB Virtual. Membro do GETED - Grupo de Estudos e Pesquisas em Tecnologia Educacional e Educação a Distância.

E-mail: blanca@ucdb.br.

Currículo: http://lattes.cnpq.br/3981955720272770

Recebido em 16 de fevereiro de 2016

Aceito em 30 de março de 2016 